Check for updates

Cite this: RSC Adv., 2017, 7, 28591

\title{
Metabolomic studies on the systemic responses of mice with oxidative stress induced by short-term oxidized tyrosine administration
}

\author{
Yuhui Yang, (D) a Biao Yan, ${ }^{a}$ Xiangrong Cheng, ${ }^{a}$ Yinyi Ding, ${ }^{a}$ Xu Tian, ${ }^{a}$ Yonghui Shi ${ }^{a b}$ \\ and Guowei Le (DD *ab
}

Oxidized tyrosine (O-Tyr) has attracted more interest in recent years because many researchers have discovered that it and its product (dityrosine) are associated with pathological conditions and metabolic disorders, especially various age-related disorders in biological systems. However, biochemical responses of an organism to short-term O-Tyr and dityrosine (Dityr) administration are unclear. Therefore, our objective is to provide insight into the effects of O-Tyr and Dityr administration on internal metabolic processes. In this study, three groups of Kunming mice were respectively given O-Tyr (320 $\mathrm{g} \mathrm{kg} \mathrm{k}^{-1}$ body weight), Dityr (320 $\mathrm{g} \mathrm{kg}^{-1}$ body weight) and sterile saline (control group) via gavage once daily for 7 consecutive days. We systematically analysed the O-Tyr and Dityr-induced metabonomic changes in mice serum and urine using proton nuclear magnetic resonance-based metabonomics approaches in conjunction with body weight, indices of oxidative damage, antioxidant capacity assessments, and antioxidant enzymes mRNA expressions. Compared with mice in the control group, O-Tyr and Dityr administration elevated oxidative damage to proteins and lipids, reduced antioxidant capacity, and suppressed antioxidant enzymes mRNA expression in mice. What's more, O-Tyr and DT administration can alter certain systemic metabolic processes in common, including enhanced fatty acid oxidation, glycolysis, glucose-alanine cycle, tricarboxylic acid (TCA) cycle metabolism, induced oxidative stress responses, elevated metabolism of vitamin- $B_{3}$, and altered gut microbiota functions. Our work provides a comprehensive view of the effects of O-Tyr and Dityr administration, implies an excess intake of oxidative proteins may result in deficiency of vitamin- $B_{3}$ in body, and reveals it is absolutely essential to avoid overly processed foods. These findings are very important for animal and human food safety.

Received 4th March 2017

Accepted 22nd May 2017

DOI: $10.1039 / \mathrm{c} 7 \mathrm{ra02665j}$

rsc.li/rsc-advances

\section{Introduction}

Food proteins are vulnerable to being oxidized during the handling, processing, cooking and storage of food materials. ${ }^{1,2}$ The oxidation of proteins leads to a variety of physicochemical modifications including protein unfolding and denaturation, cleavage of peptide bonds, formation of cross-links, and loss of functionality. ${ }^{3}$ Particularly, specific amino acid side chains are susceptible to oxidation, leading to various chemical modifications such as loss of sulfhydryl groups and amino groups, the formation of carbonyl compounds and other oxidation derivatives. ${ }^{4,5}$ Formation of oxidized protein products in the food system has been proven to cause a significant decrease in protein nutritional value in terms of availability of essential

${ }^{a}$ The Laboratory of Food Nutrition and Functional Factors, School of Food Science and Technology, Jiangnan University, 1800 Lihu Road, Wuxi 214122, China. E-mail: lgw@ jiangnan.edu.cn; Fax: +86 510 85869236; Tel: +86 51085917789

${ }^{b}$ The State Key Laboratory of Food Science and Technology, School of Food Science and Technology, Jiangnan University, Wuxi 214122, China amino acids and digestibility of oxidized proteins. ${ }^{2,5,6}$ Furthermore, consumption of oxidized protein products may have adverse health effects. ${ }^{7-10}$

Tyrosine (Tyr) is sensitive to various reactive oxygen species (ROS) and other free radicals, leading to formation of oxidized tyrosine (O-Tyr) derivatives (dityrosine, 3-nitrotyrosine, AOPPs, 3-chlorotyrosine, and 3,4-dihydroxyphenylalanine). ${ }^{11,12}$ These derivatives have been widely detected in food systems, and suggested as promising biomarkers for oxidative damage to proteins. ${ }^{13-17}$ Our past findings have shown that dietary O-Tyr could induce oxidative stress, inflammation, hepatic fibrosis, and renal fibrosis in rats. ${ }^{18,19}$ Moreover, our previous experiments also provide proof that Dityr (accounting for $22 \%$ of the total O-Tyr material) may be responsible for O-Tyr-induced injury. ${ }^{19}$ What's more, our study also found that dityrosine exposure impairs hippocampus-dependent non-spatial memory accompanied by modulation of NMDA receptor subunits and expression of brain-derived neurotrophic factor (Bdnf). ${ }^{20}$ Traditional studies on O-Tyr and Dityr administration have been performed by measuring and comparing a single or 
several biochemical markers. However, these studies did not sufficiently reflect the overall metabolic status of animals or humans exposed to O-Tyr and Dityr. Therefore, a holistic investigation of the systemic metabolic effects of O-Tyr and Dityr on a whole living bio-system is required to better understand the relationship between O-Tyr administration, Dityr administration, and human health.

Metabonomics, a powerful top-down systems biological tool based on proton nuclear magnetic resonance $\left({ }^{1} \mathrm{H}\right.$ NMR $)$ spectroscopy or mass spectrometry techniques, together with multivariate statistical analysis methods, provides an effective method for evaluating metabolic responses of living organisms to nutritional intervention. ${ }^{21,22}{ }^{1} \mathrm{H}$ NMR spectroscopy is one of the major techniques used in metabolomic studies as the spectra of biofluids or tissues contain a wealth of metabolic information and provide novel insight into the intervention effect or perturbation of diets with regard to nutrient metabolism and health. ${ }^{23}$ On the basis of ${ }^{1} \mathrm{H}$ NMR analysis, Stella et $a l .{ }^{24}$ applied an NMR-based metabonomic approach for characterization of the metabolic effects of vegetarian, low meat, and high meat diets in humans. This study illustrates the efficacy of the metabonomic approach for measuring influence of dietary modulations on short-term human metabolism. He et al. ${ }^{25}$ reported that dietary arginine administration alters the catabolism of fat and amino acids in the whole body, enhances protein synthesis in skeletal muscle, and modulates intestinal microbial metabolism in growing pigs using a ${ }^{1} \mathrm{H}$ NMR technique. A ${ }^{1} \mathrm{H}$ NMR-based metabonomic approach was also applied to evaluate global metabolic responses to L-tryptophan, cysteamine, spermine, chlorogenic acid, green tea and black tea, pea fiber and wheat bran fiber, and drinking water administration in animals. ${ }^{26-32}$ Thus, ${ }^{1} \mathrm{H}$ NMR-based metabolomics was shown to be very useful for exploring the complex relationship between nutritional intervention and metabolism in order to clarify the role of dietary components in maintaining health and developing disease. ${ }^{33}$

Therefore, we hypothesized that O-Tyr and Dityr administration causes systemic metabolic alterations in mouse urine and serum. To test this hypothesis, ${ }^{1} \mathrm{H}$ NMR spectroscopy coupled with appropriate multivariate data analysis techniques were used to examine the effects of O-Tyr and Dityr administration on biochemical profiles of urine and serum from mice. Our objective was to provide insight into the effects of O-Tyr and Dityr administration on internal metabolic processes. Metabolic profiles of O-Tyr and Dityr administration in mice can provide clues on the relationship between metabolites and nutritionally influenced biochemical O-Tyr and Dityr mechanisms, contribute baseline data for future metabolomic experiments on O-Tyr and Dityr administration, and also search for further associations between O-Tyr and Dityr administration and health or disease risk.

\section{Materials and methods}

\section{Materials}

Tyrosine was obtained from Sigma Chemical Co. (St. Louis, MO, USA). Dityr was obtained from Xiamen Huijia Biotechnology
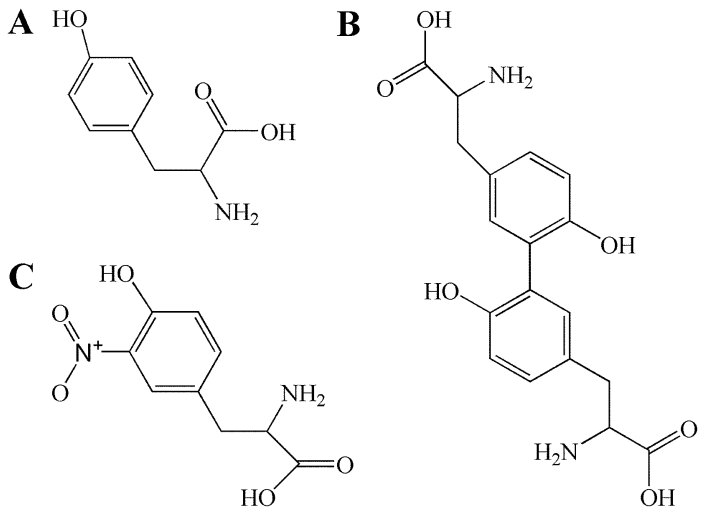

Fig. 1 Chemical structures of tyrosine (A), dityrosine (B), 3-nitrotyrosine (C).

Co., Ltd. (Xiamen, China). $\mathrm{NaH}_{2} \mathrm{PO}_{4} \cdot 2 \mathrm{H}_{2} \mathrm{O}$, and $\mathrm{K}_{2} \mathrm{HPO}_{4} \cdot 3 \mathrm{H}_{2} \mathrm{O}$ were purchased from Guoyao Chemical Co. Ltd. (Shanghai, China). TMSP [3-(trimethylsilyl) propionic- $\left(2,2,3,3-\mathrm{d}_{4}\right)$ acid sodium salt], and $\mathrm{D}_{2} \mathrm{O}(99.9 \%$ in $\mathrm{D})$ were bought from Cambridge Isotope Laboratories (MA, USA). Phosphate buffer was prepared with $\mathrm{K}_{2} \mathrm{HPO}_{4}$ and $\mathrm{NaH}_{2} \mathrm{PO}_{4}$ for their good solubility and low-temperature stability, as previously reported. ${ }^{34} \mathrm{O}-\mathrm{Tyr}$ was prepared by our laboratory according to previously reported methods. ${ }^{18,19,35}$ Chemical structures of tyrosine, dityrosine and 3-nitrotyrosine are shown in Fig. 1. ELISA kits of advanced oxidized protein products (AOPPs), Dityr and 3nitrotyrosine (3-NT) were purchased from Xiamen Huijia Bioengineering Institute (Xiamen, China). Detection kits for total antioxidant capacity (T-AOC), malondialdehyde (MDA), catalase (CAT), superoxide dismutase (SOD), glutathione peroxidase (GSH-PX), reduced glutathione (GSH) and oxidized glutathione (GSSG) were purchased from Nanjing Jiancheng Bioengineering Institute (Nanjing, China). All chemicals used in the experiments were analytical grade.

\section{Animal experiments and sample collections}

All animal experimental procedures were performed according to the National Guidelines for Experimental Animal Welfare (MOST of PR China, 2006), and approved by the Jiangnan University Institutional Animal Care and Use Committee. Female Kunming mice weighing approximately $25 \mathrm{~g}$ (4 weeks old) were purchased from Suzhou University (Suzhou, China). A total of 30 mice were housed in a SPF animal laboratory, and kept at a constant temperature of $22 \pm 2{ }^{\circ} \mathrm{C}$ and relative humidity of $50 \pm 10 \%$ with a $12 / 12 \mathrm{~h}$ light/dark cycle. After acclimatization for one week, mice were randomly divided into three groups $(n=10)$ : the control group (gavage administration of physiological saline solution once daily for 7 days), the O-Tyr group (gavage administration of O-Tyr once daily for 7 days), and the Dityr group (gavage administration of Dityr once daily for 7 days). O-Tyr and Dityr were dissolved in physiological saline solution and gavage administered at a dose of $320 \mu \mathrm{g}$ $\mathrm{kg}^{-1}$ body weight, respectively. The dosages of O-Tyr and Dityr for this study were selected based on previous reports from our 
laboratory. ${ }^{18-20}$ All mice were given free access to the same standard diet and drinking water throughout the study. The mice diet was conducted according to the general quality standard for formula feeds of laboratory animals in China (GB14924.1, 2001).

Urine samples were collected from each mouse into icecooled vessels from day 6 to day 7 of the treatment period ( 24 h). At the end of the experimental period, all mice were sacrificed after an overnight fast. Blood samples were collected (10:00-11:00 a.m.) from eyeballs under anesthesia (intraperitoneal injection of sodium pentobarbital), placed into Eppendorf tubes, kept at $4{ }^{\circ} \mathrm{C}$ for $30 \mathrm{~min}$, and centrifuged at $3500 \mathrm{~g}$ for $15 \mathrm{~min}$ at $4{ }^{\circ} \mathrm{C}$ to obtain serum. All urine and serum samples were stored at $-80{ }^{\circ} \mathrm{C}$ until ready for NMR spectroscopy analysis. Liver and kidney tissues from each group were immediately collected for subsequent analysis.

\section{Analysis of oxidative damage and total antioxidant capacity}

The concentrations of AOPPs, Dityr, and 3-NT in liver and kidney were assayed using kits and following manufacturer's instructions. The activity of T-AOC, CAT, SOD, and GSH-PX, and the concentration of GSH, GSSG, and MDA in serum, liver, and kidney also were assayed using kits and following manufacturer's instructions.

\section{Assay of mRNA expression related in antioxidant enzymes}

For determining mRNA expression, total RNA was first extracted from frozen tissues with Trizol reagent. The amount and purity of the RNA were verified by measuring the A260/A280 ratio and gel electrophoresis, respectively. Total RNA was reversetranscribed to cDNA according to manufacturer's instructions (MultiScribe Reverse Transcriptase; Applied Biosystems). The mRNA expression was quantified using Real-Time Polymerase Chain Reaction (RT-PCR). Primers were designed and synthesized by Generay Biotech Co., Ltd. (Shanghai, China). The primer sequences of CAT, SOD1, SOD2, and GSH-PX are listed in Table 1.

\section{Sample preparation and ${ }^{1} \mathrm{H}$ NMR spectroscopy}

Serum and urine samples were thawed to room temperature prior to NMR analysis, and prepared according to the method of Zhu et al. ${ }^{36}$ with a little modification. Briefly, a total of $200 \mu \mathrm{L}$ of urine was mixed with $350 \mu \mathrm{L}$ of $\mathrm{D}_{2} \mathrm{O}$ and $50 \mu \mathrm{L}$ of phosphate buffer $\left(1.5 \mathrm{M} \mathrm{Na}^{+} / \mathrm{K}^{+}\right.$buffer, $\mathrm{pH}=7.4$ ) containing $0.1 \% 3$-(trimethylsilyl) propionic-(2,2,3,3- $\left.\mathrm{d}_{4}\right)$ acid sodium salt (TSP) as a chemical shift reference. After vortexing and centrifugation at
$11000 \mathrm{~g}, 4^{\circ} \mathrm{C}$ for $10 \mathrm{~min}, 550 \mu \mathrm{L}$ of supernatant was transferred into a $5 \mathrm{~mm}$ NMR tube for analysis. Serum samples were prepared by mixing $100 \mu \mathrm{L}$ of serum with $500 \mu \mathrm{L}$ of saline solution containing $75 \% \mathrm{D}_{2} \mathrm{O}$ as a field frequency lock. These mixtures were vortexed and centrifuged at $11000 \mathrm{~g}, 4{ }^{\circ} \mathrm{C}$ for $10 \mathrm{~min}$, and then $550 \mu \mathrm{L}$ of supernatant from each sample was transferred into a $5 \mathrm{~mm}$ NMR tube for analysis.

In this study, NMR detection of all samples was conducted by Wuhan Zhongke Metaboss Technology CO., LTD. All onedimensional ${ }^{1} \mathrm{H}$ NMR spectra of urine and serum samples were recorded at $298 \mathrm{~K}$ on a Bruker Avance II $600 \mathrm{MHz}$ NMR spectrometer (Bruker Biospin, Germany) operating at 600.58 $\mathrm{MHz}$ for proton frequency and equipped with a $5 \mathrm{~mm}$ broadband observe probe. The ${ }^{1} \mathrm{H}$ NMR spectra of urine samples were recorded using water-suppressed standard one-dimensional nuclear overhauser effect spectroscopy (NOESYPR1D) pulse sequence (recycle delay- $90^{\circ}-t_{1}-90^{\circ}-t_{\mathrm{m}}-90^{\circ}$-acquisition) for representation of the total metabolite composition with a recycle delay of $2 \mathrm{~s}, t_{1}$ of $3 \mu \mathrm{s}$, mixing time $\left(t_{\mathrm{m}}\right)$ of $100 \mathrm{~ms}$, and $90^{\circ}$ pulse length of $12.00 \mathrm{~ms}$. A total of 64 transients were collected in $32 \mathrm{k}$ data points using a spectral width of $8417.5 \mathrm{~Hz}$ and an acquisition time of 3.89 s. For serum, a waterpresaturated Carr-Purcell-Meiboom-Gill (CPMGPR1D) pulse sequence [recycle delay- $90^{\circ}-\left(\tau-180^{\circ}-\tau\right)_{n}$-acquisition] was employed to attenuate the NMR signals from macromolecules. These spectra were measured using a spin-spin relaxation delay $(2 n \tau)$ of $80 \mathrm{~ms}$ and a spin-echo delay $\tau$ of $400 \mu \mathrm{s}$. A total 32 transients were collected into $32 \mathrm{k}$ data points using a spectral width of $9615.4 \mathrm{~Hz}$ with a relaxation delay of $3 \mathrm{~s}$. Metabolite assignments were usually made by considering chemical shifts, coupling constants, and relative intensities, as in previous reports. ${ }^{37,38}$

\section{Data processing for metabonomic analysis}

Free induction decays were multiplied by an exponential window function with a $1 \mathrm{~Hz}$ line-broadening factor prior to Fourier transformation. All ${ }^{1} \mathrm{H}$ NMR spectra from urine and serum samples were then phase-adjusted and baselinecorrected manually employing Mestrenova 6.1.1 software (Mestrelab Research S.L., Spain). A urinary spectral region $\delta 0.5$ to $\delta 9.5$ was bucketed into regions with $0.01 \mathrm{ppm}$ widths, and a serum spectral region $\delta 0.5$ to $\delta 8.5$ was integrated into regions with equal $0.01 \mathrm{ppm}$ widths. TSP with a chemical shift at $\delta 0.00$ was used as a spectral reference for urine, whereas NMR spectra of the serum were referenced to the methyl proton of L-lactate at $\delta 1.33$. Regions containing water $(\delta 4.68$ to $\delta 5.20)$ were removed to avoid the effects of imperfect water suppression. The urea

Table 1 Sequences of primers used in quantitative real-time reverse transcription PCR

\begin{tabular}{lll}
\hline Gene symbol & Forward primer $\left(5^{\prime}-3^{\prime}\right)$ & Reverse primer $\left(5^{\prime}-3^{\prime}\right)$ \\
\hline CAT & CCTTCAAGTTGGTTAATGCAGA & CAAGTTTTTGATGCCCTGGT \\
SOD1 & ATGGCGATGAAAGCGGTGT & CCTTGTGTATTGTCCCCATACTG \\
SOD2 & CAGACCTGCCTTACGACTATGG & CTCGGTGGCGTTGAGATTGTT \\
GSH-PX & TTTCCCGTGCAATCAGTTC & TCGGACGTACTTGAGGGAAT
\end{tabular}


signal was excluded to avoid any contributions of urea to intergroup differentiations in order to eliminate the effects of variation in urea signals caused by partial cross-solvent saturation via solvent-exchanging protons. Discarded regions in the urine spectra included $\delta 4.68$ to $\delta 5.00$ for $\mathrm{H}_{2} \mathrm{O}$ and $\delta 5.70$ to $\delta 6.00$. Subsequently, all remaining regions of the spectra were normalized to the total integrated area of the spectra to reduce any significant concentration differences before multivariate data analysis.

Normalized NMR datasets were exported to TXT files using Mestrenova 6.1.1 software, imported into Microsoft Office Excel 2007 (Microsoft Corporation, Redmond, Washington, USA) for integration, and then imported into the software package SIMCA-P 13.0 (Umetrics, Umea, Sweden) for multivariate data analysis. Initially, in a unsupervised manner, principal component analysis (PCA) was performed on the dataset to generate an overview and identify possible outliers within the dataset. $^{39}$ Each point in the score plots represented an individual spectrum of a sample. If one point position was outside the Hotelling's $T^{2}$ ellipse on the score plot, it was removed from the dataset. Subsequently, partial latent structure-discriminate analysis (PLS-DA) was conducted to distinguish experimental group mice and control group mice in a supervised manner. The quality of the model was evaluated by the parameters: $R^{2} X$ (representing the total explained variation) and $Q^{2}$ (standing for the model predictability). $R^{2}>0.50$ and $Q^{2}>0.50$ indicates that the model is robust and has good fitness and prediction. Leaveone-out cross validation and the response of the permutation test (200 cycles) should be used to evaluate the reliability of the model when a small number of samples is adopted. Furthermore, a supervised pattern recognition approach known as an orthogonal projection to latent structures discriminant analysis (OPLS-DA) was used to improve classification of the different groups while screening biomarkers. With an aim to discover potential variables contributing to the differentiation, we generated an $S$-plot for the OPLS-DA model used to define metabolites significantly contributing to the separation of the two groups. ${ }^{40}$ Metabolites with VIP (variable importance in the projection) values $\geq 1.0$ were regarded as significant in this study. VIP is a computation of the influence of every $X$ term in the model on the $Y$ variable. Larger VIP values indicate a greater influence of a term $X$ on the $Y$ variable. ${ }^{41}$ Meanwhile, an

Table 2 Effects of O-Tyr and DT administration on body weight in mice ${ }^{a}$

\begin{tabular}{lcccc}
\hline Parameters & Control group & O-Tyr group & $P^{\mathrm{a}}$ value & Dityr group \\
\hline Initial weight $(\mathrm{g})$ & $25.53 \pm 0.52$ & $25.60 \pm 0.37$ & 0.906 & $P^{\mathrm{b}}$ value \\
Finish weight $(\mathrm{g})$ & $26.99 \pm 0.35$ & $26.86 \pm 0.58$ & 0.852 & 0.949 \\
& & & 0.567
\end{tabular}

${ }^{a}$ Data from each group $(n=10)$ were averaged and presented as means \pm SEM. $P$ values $<0.05$ were regarded as significant statistical significance.

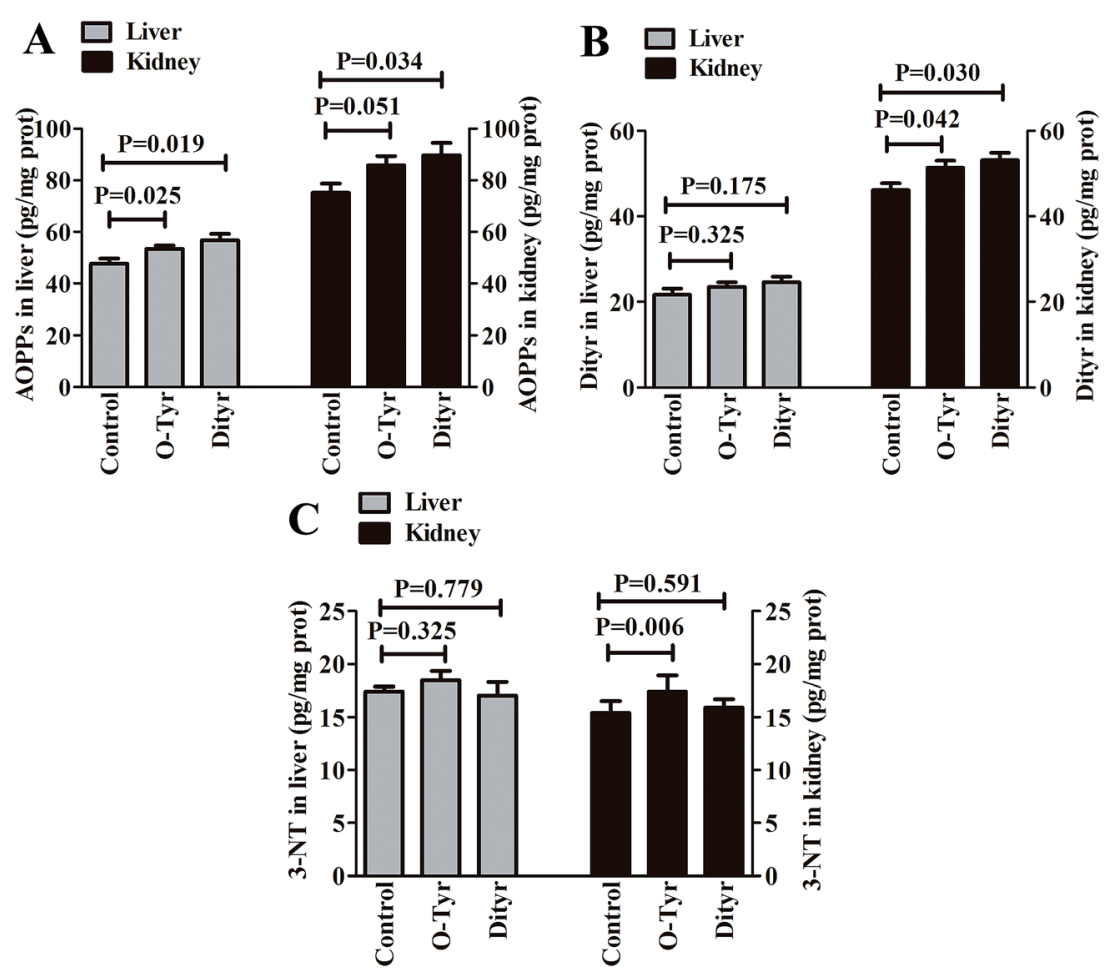

Fig. 2 Effects of O-Tyr and DT administration on the concentrations of AOPPs (A), Dityr (B), and 3-NT (C) in mice liver and kidney. Data from each group $(n=10)$ were averaged and presented as means \pm SEM. $P$ values $<0.05$ were regarded as significant statistical significance. 

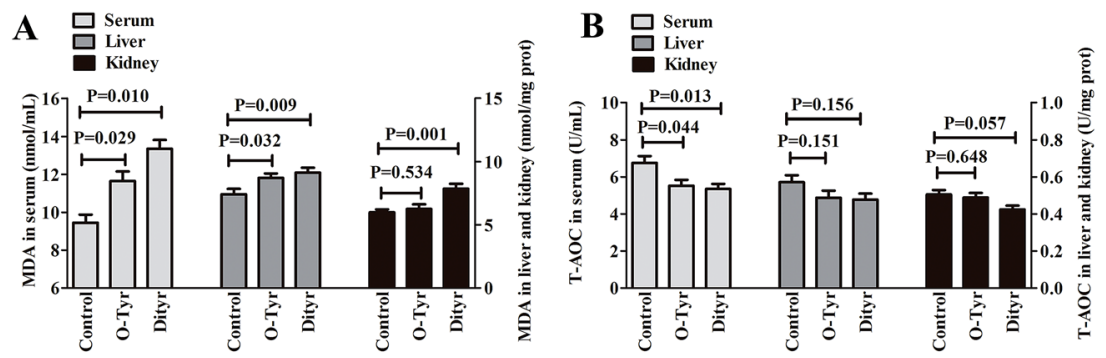

\section{C 吕 Lerum}

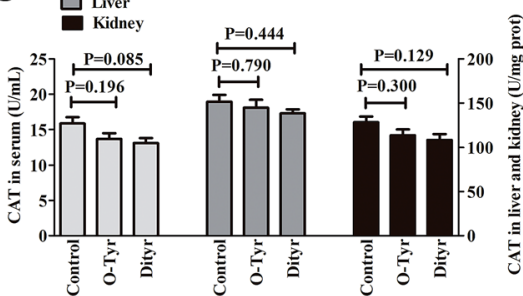

D ${ }^{\mathrm{S}} \mathrm{Serum}$

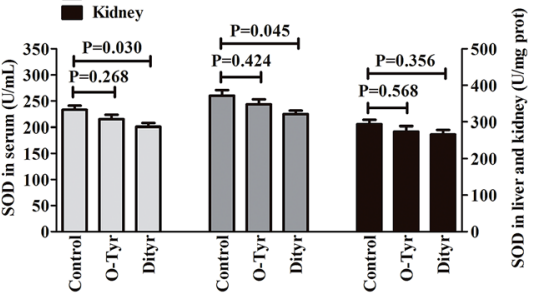

\section{E $\begin{gathered}\text { Serum } \\ \text { Liver } \\ \text { Kidney }\end{gathered}$}
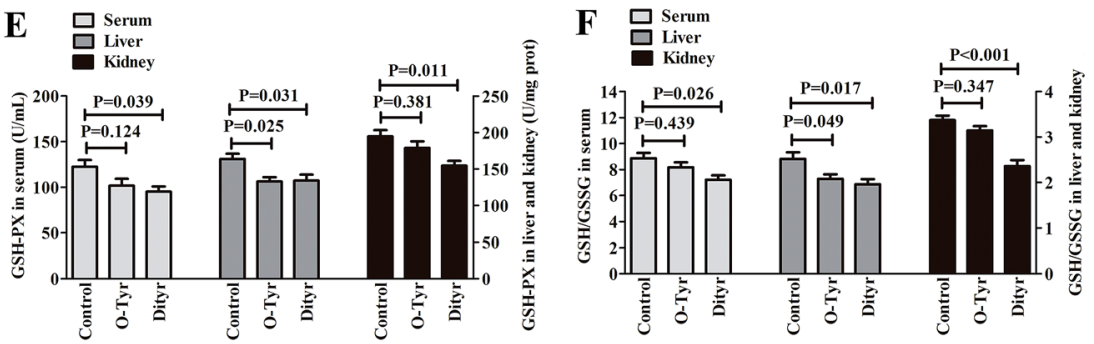

Fig. 3 Effects of O-Tyr and DT administration on MDA (A) content, T-AOC (B), CAT (C), SOD (D) and GSH-PX (E) activity, and GSH/GSSG value (F) in mice serum, liver and kidney. Data from each group $(n=10)$ were averaged and presented as means \pm SEM. $P$ values $<0.05$ were regarded as significant statistical significance.

independent sample $t$-test was further used to validate those major contributing variables from the PLS-DA and OPLS-DA models using the software of SPSS 17.0 (SPSS Inc., Chicago,
USA). Values of $P<0.05$ were regarded as significant statistical significance. Only those metabolites that meet the two criteria are eventually considered as potential biomarkers. ${ }^{42}$
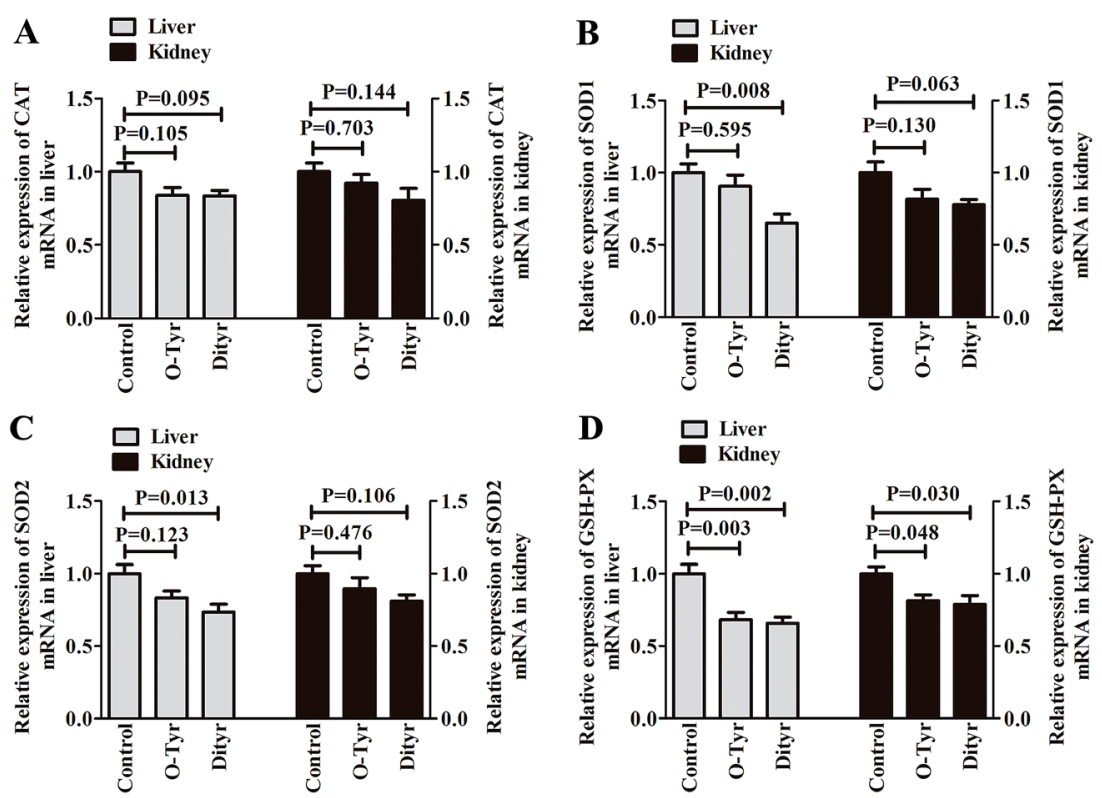

Fig. 4 Effects of O-Tyr and DT administration on antioxidant enzymes mRNA expressions of CAT (A), SOD1 (B), SOD2 (C) and GSH-PX (D) in the liver and kidney. Data from each group $(n=10)$ were averaged and presented as means \pm SEM. $P$ values $<0.05$ were regarded as significant statistical significance. 


\section{Statistical analysis}

All other experimental results were also statistically analyzed using the software of SPSS 17.0. Statistical significance was determined by a one-way analysis of variance (ANOVA) followed by the Tuckey post hoc test. ${ }^{\mathbf{4 3}}$ Data were presented as mean \pm standard error of the mean (SEM). $P$ values less than 0.05 were accepted as statistically significant.

\section{Results}

\section{Effects of O-Tyr and DT administration on body weights in} mice

Effects of O-Tyr and DT administration on the body weight of mice are listed in Table 2 . At the beginning of the study, the body weights of mice in the O-Tyr group and DT group were the same as in the control group. At the end of the experiments, OTyr and DT administration had a tendency to decrease the body weights of mice, but there were no statistically significant differences between the three groups $(P>0.05)$.

\section{Effects of O-Tyr and DT administration on protein oxidation of mice liver and kidney}

Effects of O-Tyr and DT administration on the concentrations of AOPPs, Dityr and 3-NT in mice liver and kidney are shown in Fig. 2. Compared with control group, O-Tyr administration significantly increased the concentration of AOPPs in liver, and the concentrations of Dityr and 3-NT in kidney $(P<0.05)$. DT administration significantly increased the concentration of AOPPs in liver, and the concentrations of AOPPs and Dityr in kidney $(P<0.05)$.

\section{Effects of O-Tyr and DT administration on the antioxidant capacity of mice serum, liver, and kidney}

Effects of O-Tyr and DT administration on T-AOC, CAT, SOD, and GSH-PX activity, and GSH/GSSG and MDA content in mice serum, liver, and kidney are shown in Fig. 3. O-Tyr administration significantly decreased the activity of T-AOC in serum and GSH-PX in liver, and reduced the value of GSH/GSSG in liver, and increased the content of MDA in serum and liver, compared to the control group $(P<0.05)$. DT administration significantly decreased the activity of T-AOC in serum, and declined the activity of SOD in serum and liver, decreased the activity of GSH-PX in serum, liver, and kidney and reduced the value of GSH/GSSG in serum, liver, and kidney, and increased the content of MDA in serum, liver, and kidney $(P<0.05)$.

\section{Effects of O-Tyr and DT administration on the antioxidant enzymes mRNA expression of mice liver and kidney}

Effects of O-Tyr and DT administration on the antioxidant enzymes mRNA expression of mice liver and kidney are shown

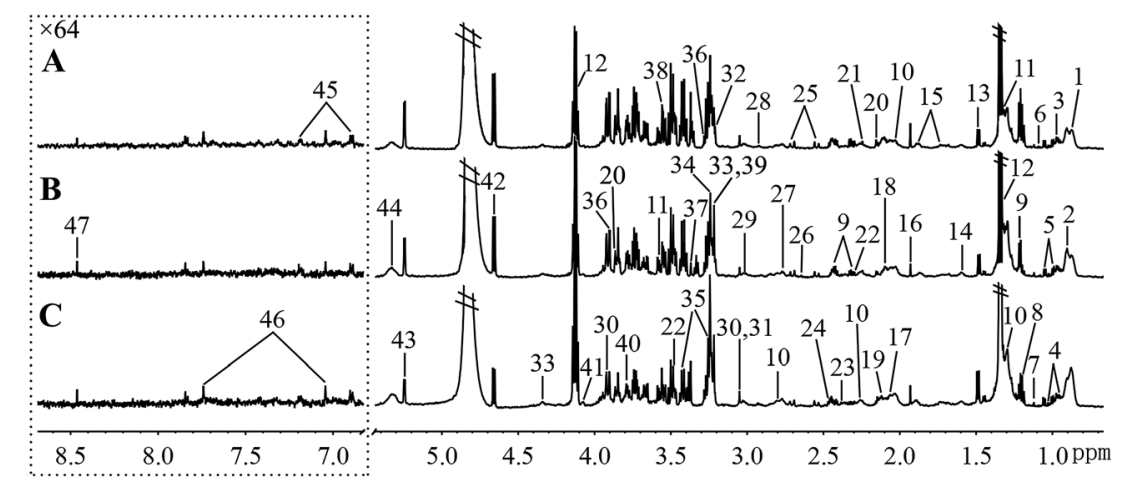

Fig. 5 Typical $600 \mathrm{MHz}{ }^{1} \mathrm{H}$ NMR spectra of serum taken from mice with the control group (A), O-Tyr group (B) and DT group (C). The region of $\delta$ 6.83-8.67 was magnified 64 times compared with corresponding region of $\delta 0.71-5.44$ for the purpose of clarity. Metabolite keys are given in Table 3.

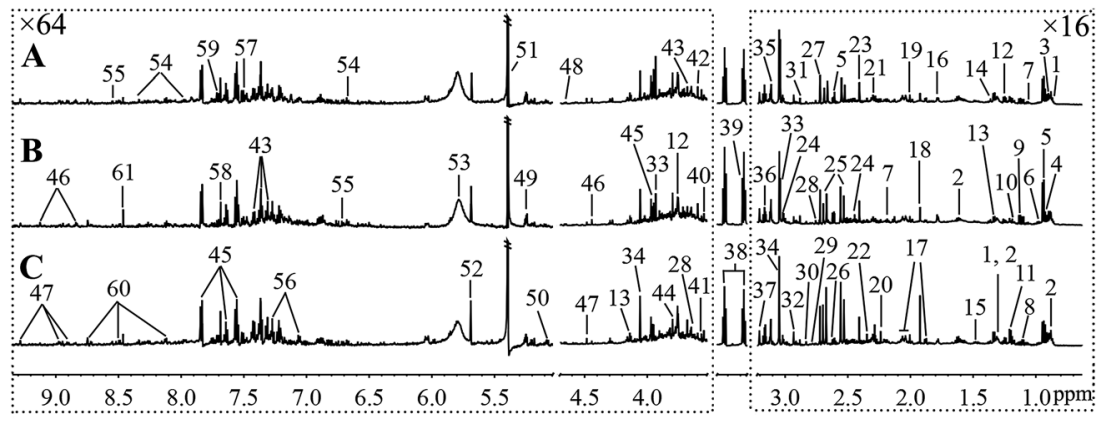

Fig. 6 Typical $600 \mathrm{MHz}^{1} \mathrm{H}$ NMR spectra of urine taken from mice with the control group (A), O-Tyr group (B) and DT group (C). The regions of $\delta$ 0.64-3.21 and $\delta 3.53-9.33$ were magnified 16 and 64 times compared with corresponding region of $\delta 3.24-3.49$ for the purpose of clarity, respectively. Metabolite keys are given in Table 4. 
in Fig. 4. Quantitative RT-PCR analysis showed that O-Tyr administration significantly reduced the antioxidant enzyme of GSH-PX expression in liver and kidney tissues $(P<0.05)$. DT administration significantly decreased the antioxidant enzymes of SOD1, SOD2 and GSH-PX expressions in liver tissue, and declined the antioxidant enzyme of GSH-PX expression in kidney tissue $(P<0.05)$.

\section{${ }^{1} \mathrm{H}$ NMR spectra of urine and serum samples}

Fig. 5 and 6, respectively, show representative ${ }^{1} \mathrm{H}$ NMR spectra of serum and urine samples taken from randomly selected mice in the control group, O-Tyr group, and DT group. A total of 47 metabolites in serum and 61 metabolites in urine were unambiguously assigned from the ${ }^{1} \mathrm{H}$ NMR spectra. Assignment of metabolites was made on the basis of comparisons with the published literature $\mathbf{4 4 - 4 7}^{\mathbf{4}}$ and existing databases (such as the

Table 3 Metabolites of mice in serum ${ }^{a}$

\begin{tabular}{|c|c|c|c|}
\hline Keys & Metabolites & Moieties & $\delta^{1} \mathrm{H}(\mathrm{ppm})$ and multiplicity \\
\hline 1 & LDL & $\mathrm{CH}_{3}\left(\mathrm{CH}_{2}\right)_{n}$ & $0.88(\mathrm{~m})$ \\
\hline 2 & VLDL & $\mathrm{CH}_{3} \mathrm{CH}_{2} \mathrm{CH}_{2} \mathrm{C}=$ & $0.90(\mathrm{t})$ \\
\hline 4 & Isoleucine & $\alpha \mathrm{CH}, \beta \mathrm{CH}, \beta \mathrm{CH}_{3}, \gamma \mathrm{CH}_{2}, \delta \mathrm{CH}_{3}$ & $3.68(\mathrm{~d}), 1.99(\mathrm{~m}), 1.01(\mathrm{~d}), 1.26(\mathrm{~m}), 1.47(\mathrm{~m}), 0.94(\mathrm{t})$ \\
\hline 5 & Valine & $\alpha \mathrm{CH}_{3}, \beta \mathrm{CH}, \gamma \mathrm{CH}_{3}$ & $3.62(\mathrm{~d}), 2.28(\mathrm{~m}), 0.99(\mathrm{~d}), 1.04(\mathrm{~d})$ \\
\hline 6 & Propionate & $\mathrm{CH}_{3}, \mathrm{CH}_{2}$ & $1.08(\mathrm{t}), 2.18(\mathrm{q})$ \\
\hline 9 & 3-Hydroxybutyrate & $\alpha \mathrm{CH}_{2}, \beta \mathrm{CH}, \gamma \mathrm{CH}_{3}$ & $2.31(\mathrm{dd}), 2.42(\mathrm{dd}), 4.16(\mathrm{~m}), 1.21(\mathrm{~d})$ \\
\hline \multirow[t]{2}{*}{10} & Lipids & $\mathrm{CH}_{2}^{*} \mathrm{CH}_{2} \mathrm{CO}, \mathrm{CH}_{2}-\mathrm{C}=\mathrm{C}$ & $1.29(\mathrm{~m}), 1.58(\mathrm{~m}), 2.02(\mathrm{~m})$ \\
\hline & & $\mathrm{CH}_{2}-\mathrm{C}=\mathrm{O}, \mathrm{CH}-\mathrm{O}-\mathrm{CO}$ & $2.25(\mathrm{~m}), 2.77(\mathrm{~m})$ \\
\hline 11 & Threonine & $\alpha \mathrm{CH}, \beta \mathrm{CH}, \gamma \mathrm{CH}_{3}$ & $1.32(\mathrm{~d}), 4.25(\mathrm{~m}), 3.58(\mathrm{~d})$ \\
\hline 12 & Lactate & $\alpha \mathrm{CH}, \beta \mathrm{CH}_{3}$ & $1.33(\mathrm{~d}), 4.11(\mathrm{q})$ \\
\hline 13 & Alanine & $\alpha \mathrm{CH}, \beta \mathrm{CH}_{3}$ & $3.77(\mathrm{q}), 1.48(\mathrm{~d})$ \\
\hline 18 & $O$-Acetyl glycoprotein & $\mathrm{CH}_{3}$ & $2.09(\mathrm{~s})$ \\
\hline 19 & Glutamate & $\alpha \mathrm{CH}, \beta \mathrm{CH}_{2}, \gamma \mathrm{CH}_{2}$ & 3.75(m), 2.12(m), 2.35(m) \\
\hline 20 & Methionine & $\alpha \mathrm{CH}, \beta \mathrm{CH}_{2}, \gamma \mathrm{CH}_{2}, \mathrm{~S}-\mathrm{CH}_{3}$ & $3.87(\mathrm{t}), 2.16(\mathrm{~m}), 2.65(\mathrm{t}), 2.14(\mathrm{~s})$ \\
\hline 21 & Acetone & $\mathrm{CH}_{3}$ & $2.24(\mathrm{~s})$ \\
\hline 22 & Acetoacetate & $\mathrm{CH}_{3}, \mathrm{CH}_{2}$ & $2.29(\mathrm{~s}), 3.49(\mathrm{~s})$ \\
\hline 23 & Pyruvate & $\mathrm{CH}_{3}$ & $2.38(\mathrm{~s})$ \\
\hline 24 & Glutamine & $\alpha \mathrm{CH}, \beta \mathrm{CH}_{2}, \gamma \mathrm{CH}_{2}$ & $3.68(\mathrm{t}), 2.15(\mathrm{~m}), 2.45(\mathrm{~m})$ \\
\hline 25 & Citrate & $\mathrm{CH}_{2}$ & $2.54(\mathrm{~d}), 2.69(\mathrm{~d})$ \\
\hline 26 & Methylamine & $\mathrm{CH}_{3}$ & $2.64(\mathrm{~s})$ \\
\hline 27 & Dimethylamine & $\mathrm{CH}_{3}$ & $2.73(\mathrm{~s})$ \\
\hline 28 & Trimethylamine & $\mathrm{CH}_{3}$ & $2.92(\mathrm{~s})$ \\
\hline 29 & Albumin & Lysyl- $\mathrm{CH}_{2}$ & $3.02(\mathrm{~s})$ \\
\hline 38 & Glycine & $\mathrm{CH}_{2}$ & $3.56(\mathrm{~s})$ \\
\hline 39 & Phosphorylcholine & $\mathrm{N}\left(\mathrm{CH}_{3}\right)_{3}, \mathrm{OCH}_{2}, \mathrm{NCH}_{2}$ & $3.22(\mathrm{~s}), 4.21(\mathrm{t}), 3.61(\mathrm{t})$ \\
\hline 40 & Ornithine & $\mathrm{CH}_{2}, \alpha \mathrm{CH}$ & $3.80(\mathrm{~s}), 3.79(\mathrm{t})$ \\
\hline 41 & Myo-inositol & 5-CH, 4,6-CH, 2-CH & $3.30(\mathrm{t}), 3.63(\mathrm{t}), 4.06(\mathrm{t})$ \\
\hline 42 & $\beta$-Glucose & 2-CH, 1-CH & $3.25(\mathrm{dd}), 4.65(\mathrm{~d})$ \\
\hline 43 & $\alpha$-Glucose & $1-\mathrm{CH}$ & $5.26(\mathrm{~d})$ \\
\hline 44 & Unsaturated lipids & $=\mathrm{C}-\mathrm{CH}_{2}-\mathrm{C}=,-\mathrm{CH}=\mathrm{CH}-$ & $5.19(\mathrm{~m}), 5.31(\mathrm{~m})$ \\
\hline 45 & Tyrosine & 2,6-CH, 3,5-CH & $7.19(\mathrm{dd}), 6.90(\mathrm{~d})$ \\
\hline 46 & 1-Methylhistidine & $4-\mathrm{CH}, 2-\mathrm{CH}$ & $7.04(\mathrm{~s}), 7.75(\mathrm{~s})$ \\
\hline 47 & Formate & $\mathrm{CH}$ & $8.46(\mathrm{~s})$ \\
\hline
\end{tabular}

${ }^{a}$ LDL, low density lipoprotein; VLDL, low density lipoprotein; TMAO, trimethylamine-N-oxide; GPC, glycerophosphorylcholine; s, singlet; d, doublet; t, triplet; q, quartet; dd, doublet of doublets; m, multiplet. 
Table 4 Metabolites of mice in urine ${ }^{a}$

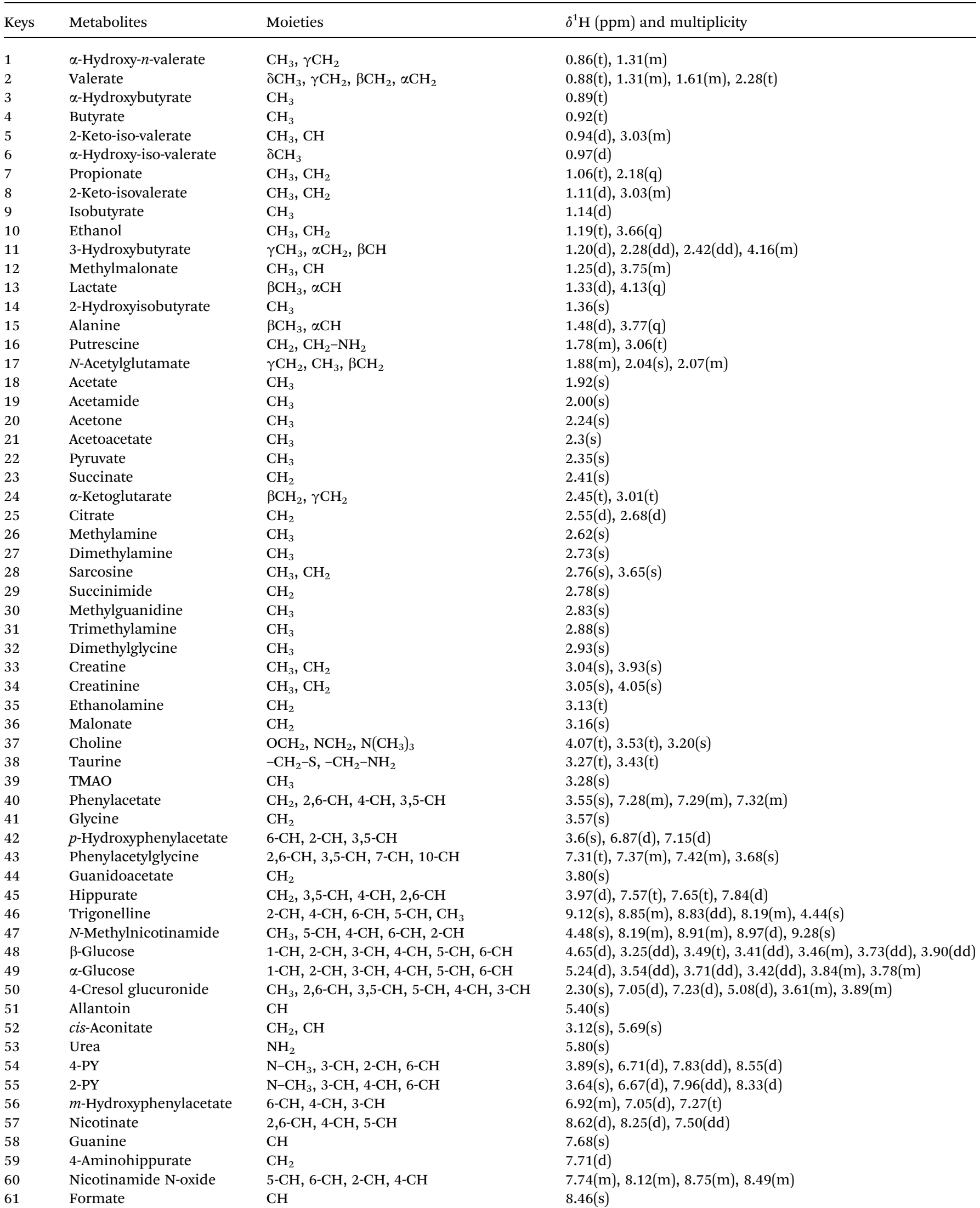

${ }^{a}$ TMAO, trimethylamine-N-oxide; 4-PY, $N^{1}$-methyl-4-pyridone-5-carboxamide; 2-PY, $N^{1}$-methyl-2-pyridone-5-carboxamide; s, singlet; d, doublet; t, triplet; q, quartet; dd, doublet of doublets; $\mathrm{m}$, multiplet. 


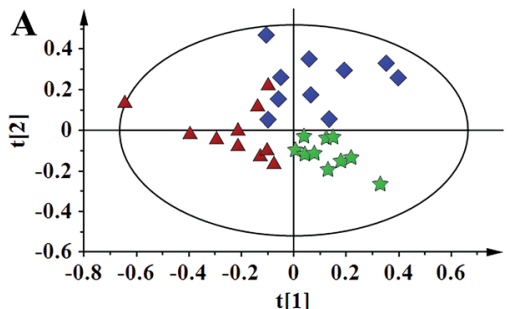

$\star$ Control O-Tyr $\triangle$ Dityr
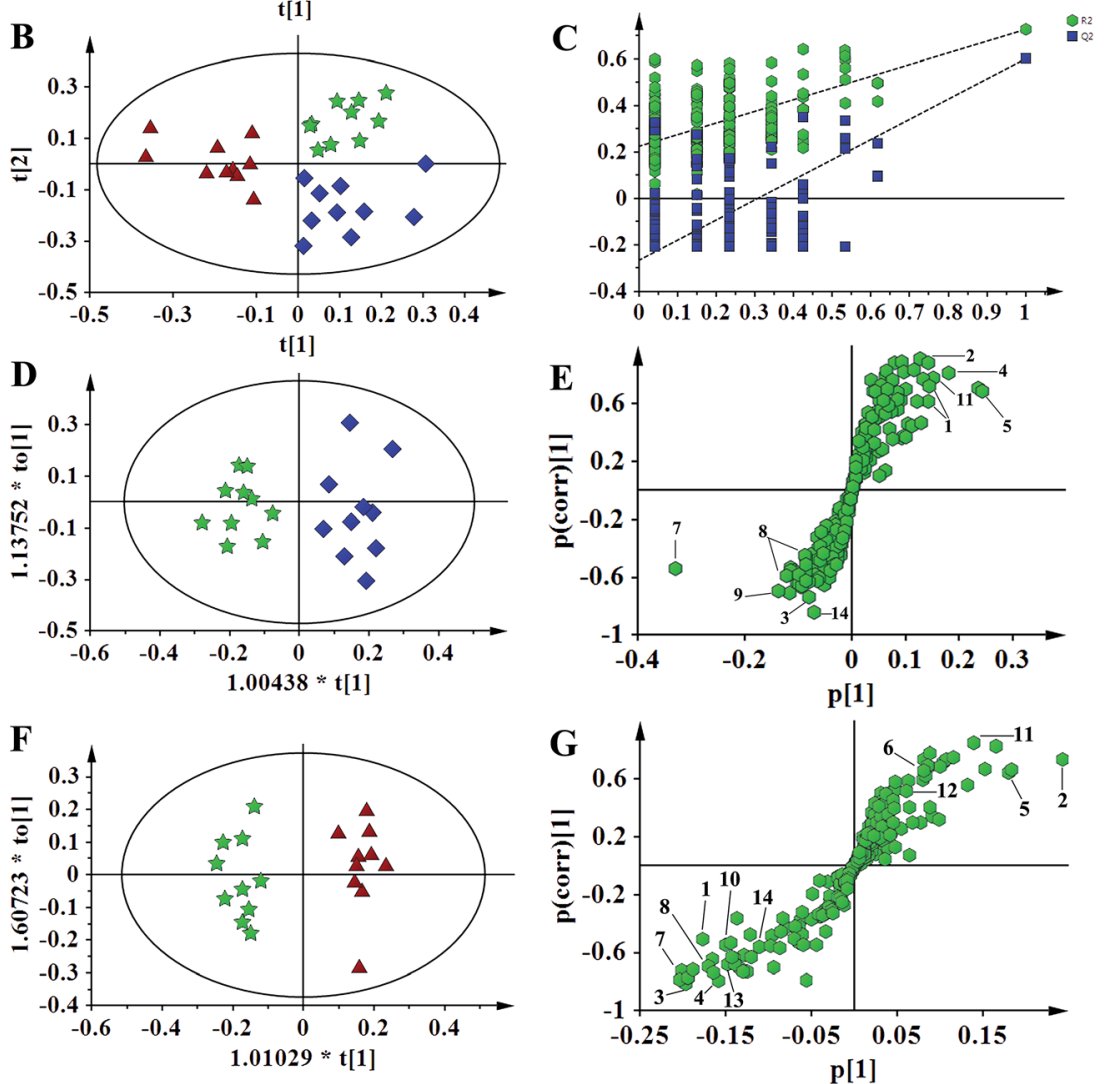

Fig. 7 PCA score plots (A: $\left.R^{2} X=0.824, Q^{2}=0.451\right)$, PLS-DA score plots (B: $\left.R^{2} X=0.428, R^{2} Y=0.734 Q^{2}=0.571\right)$, PLS-DA validation plots (C, permutation number: 200), OPLS-DA (D: $R^{2} X=0.436, R^{2} Y=0.915 Q^{2}=0.780 ; \mathrm{F}: R^{2} X=0.497, R^{2} Y=0.962 Q^{2}=0.863$ ), and corresponding $S-$ plot ( $E$ and $G$ ) based on the ${ }^{1} \mathrm{H}$ NMR spectra of serum metabolites obtained from the control group (red circles), $O$-Tyr group (blue triangles) and Dityr group (black squares). (1) isoleucine; (2) valine; (3) propionate; (4) isobutyrate; (5) 3-hydroxybutyrate; (6) alanine; (7) acetoacetate; (8) citrate; (9) methylamine; (10) trimethylamine; (11) choline; (12) GPC; (13) betaine; (14) $\alpha$-glucose.

Human Metabolome Data Base). ${ }^{48}$ In addition, for exact assignment purposes, five two-dimensional (2D) NMR spectra including ${ }^{1} \mathrm{H}-{ }^{1} \mathrm{H}$ J-resolved spectroscopy (J-Res), ${ }^{1} \mathrm{H}-{ }^{1} \mathrm{H}$ correlation spectroscopy (COSY), ${ }^{1} \mathrm{H}-{ }^{1} \mathrm{H}$ total correlation spectroscopy (TOCSY), ${ }^{1} \mathrm{H}-{ }^{13} \mathrm{C}$ heteronuclear single quantum coherence spectroscopy (HSQC), and ${ }^{1} \mathrm{H}^{-}{ }^{13} \mathrm{C}$ heteronuclear multiple bond correlation spectroscopy (HMBC) were obtained from previous studies as ref. 49-51. Their chemical shifts, peak multiplicity, and the corresponding ${ }^{1} \mathrm{H}$ NMR signal multiplicities are listed in Tables 3 and 4, respectively. The spectra of serum samples contained resonances from several amino acids, short-chain fatty acids, nitrogenous compounds, acetyl glycoproteins, lipoproteins, glucose, ketones, TCA cycle intermediates, and choline metabolites. The urine samples mainly contained several amino acids, glucose, organic acids, allantoin, TCA cycle intermediates, short-chain fatty acids, nitrogenous compounds, and metabolites of amino acids, choline, and vitamin $\mathrm{B}_{3}$. In order to obtain more details about metabonomic changes in $\mathrm{O}$ Tyr and DT group mice, multivariate data analyses were further conducted on ${ }^{1} \mathrm{H}$ NMR data for serum and urine.

\section{Multivariate data analysis of ${ }^{1} \mathrm{H}$ NMR data}

${ }^{1} \mathrm{H}$ NMR spectral data sets from serum and urine were initially analyzed by PCA. The PCA score plots of serum and urine (Fig. 7A and 8A, respectively) showed there were no outliers within the dataset, and separations were absent in the metabolic serum and urine profiles of mice from the control group, O-Tyr group, and DT group. Therefore, PLS-DA was applied to explore the intrinsic differences between these three groups. Samples from different groups were separated and classified into three distinct clusters presented in the PLS-DA score plot (Fig. 7B and 8B, respectively). The model parameters (serum: 


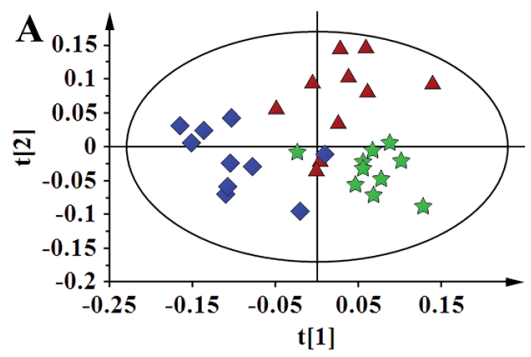

$\star$ Control $\diamond$ O-Tyr $\Delta$ Dityr
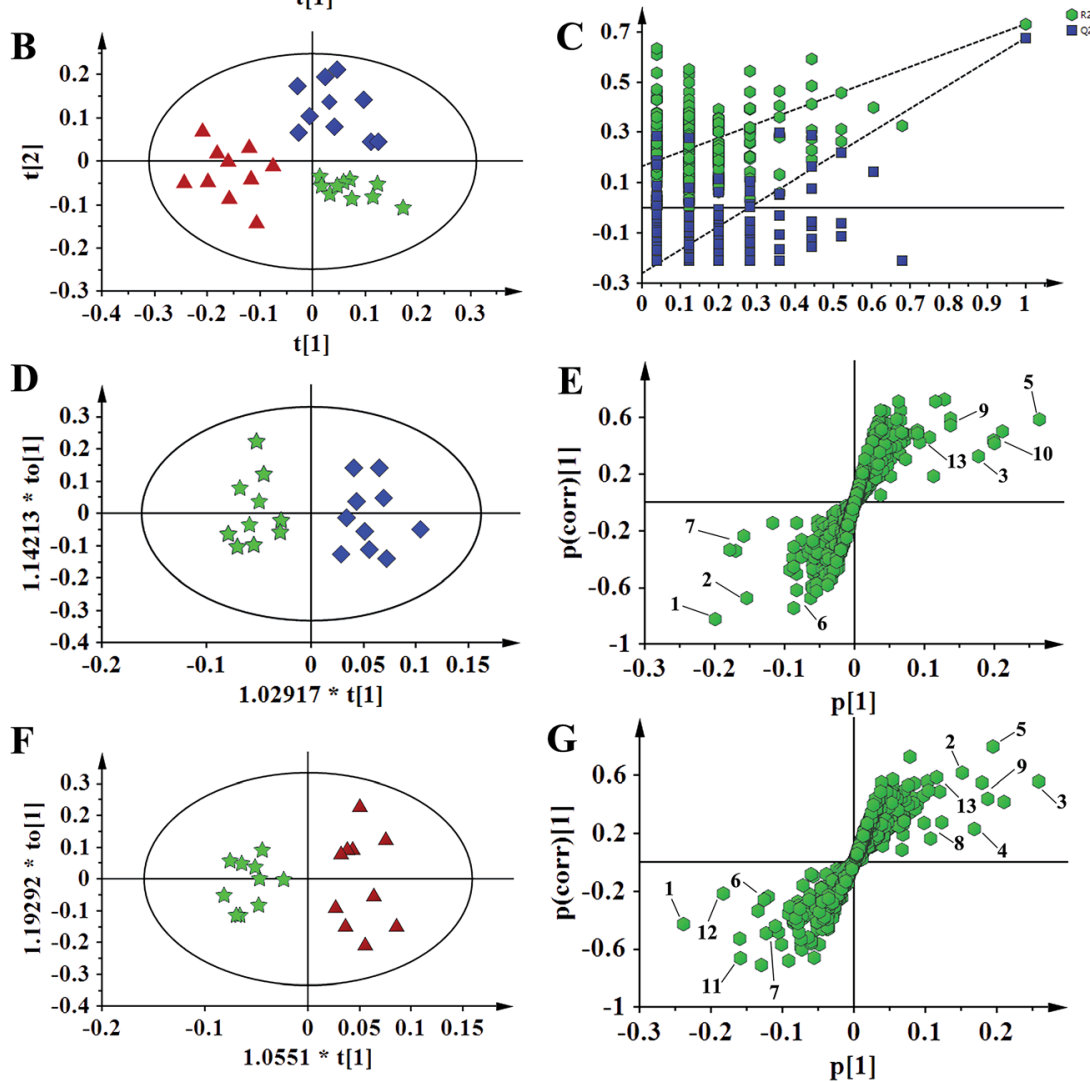

Fig. 8 PCA score plots (A: $\left.R^{2} X=0.679, Q^{2}=0.430\right)$, PLS-DA score plots (B: $\left.R^{2} X=0.591, R^{2} Y=0.753 Q^{2}=0.704\right)$, PLS-DA validation plots (C, permutation number: 200), OPLS-DA ( $\left.\mathrm{D}: R^{2} X=0.541, R^{2} Y=0.918 Q^{2}=0.468 ; \mathrm{F}: R^{2} X=0.451, R^{2} Y=0.898 Q^{2}=0.572\right)$ and corresponding $S$ plot ( $E$ and $G$ ) based on the ${ }^{1} \mathrm{H}$ NMR spectra of urine metabolites obtained from the control group (red circles), $O$-Tyr group (blue triangles) and Dityr group (black squares). (1) acetoacetate; (2) pyruvate; (3) succinate; (4) citrate; (5) allantoin; (6) 4-PY; (7) 2-PY; (8) p-hydroxyphenylacetate; (9) m-hydroxyphenylacetate; (10) N-methylnicotinamide; (11) hippurate; (12) nicotinamide $\mathrm{N}$-oxide; (13) trigonelline.

$R^{2} X=0.428, R^{2} Y=0.734, Q^{2}=0.571$. And urine: $R^{2} X=0.591$, $R^{2} Y=0.753, Q^{2}=0.704$ ) and the validated models (permutation number: 200) indicated no over fitting (Fig. 7C and 8C), respectively. All the results indicated the existence of differences between the three groups.

Furthermore, spectral data sets from serum and urine were analyzed by OPLS-DA to maximize discrimination between the three groups (Fig. 7D and $\mathrm{F}$ and $8 \mathrm{D}$ and $\mathrm{F}$ ), respectively. The supervised model of OPLS-DA could develop a better separation into two clusters and contribute to the discovery of biomarkers. The O-Tyr group and DT group were well separated from the control group in the OPLS-DA scores plot of spectral data sets from serum and urine, as well as in permutation tests and variance analysis of the cross-validated residuals (CV-ANOVA) ( $P$ $<0.05$ ), respectively. Metabolites responsible for a significant contribution to separation of the two groups are indicated in the corresponding $S$-plots (Fig. 7E and G and 8E and G) and marked with a number. The VIP statistics of the first principal component of OPLS-DA model (threshold $\geq 1$ ), together with the $P$ value of the independent sample $t$-test (threshold $<0.05$ ) were used for selecting significant variables responsible for group separation. ${ }^{52}$ The identified potential markers in serum and urine are listed in Tables 5 and 6, respectively. O-Tyr administration significantly increased the serum levels of propionate, isobutyrate, 3-hydroxybutyrate, acetoacetate, citrate, methylamine and choline, and decreased the serum levels of isoleucine, valine and $\alpha$-glucose compared with the control group $(P<$ 0.05 , Table 5). Moreover, O-Tyr administration significantly increased the urine levels of acetoacetate, pyruvate, succinate, allantoin, $N^{1}$-methyl-4-pyridone-5-carboxamide (4-PY), $N^{1}$ - 
Table 5 List of differential serum metabolites among different groups ${ }^{a}$

\begin{tabular}{|c|c|c|c|c|c|c|c|}
\hline Metabolites & NMR chemical shift $(\delta)$ & \multicolumn{3}{|c|}{ O-Tyr vs. control } & \multicolumn{3}{|c|}{ Dityr vs. control } \\
\hline Valine & $1.04(\mathrm{~d})$ & 1.97 & 0.049 & $\downarrow$ & 2.64 & 0.008 & $\downarrow$ \\
\hline Propionate & $1.08(\mathrm{t})$ & 1.39 & 0.045 & $\uparrow$ & 1.76 & 0.033 & $\uparrow$ \\
\hline Isobutyrate & $1.12(\mathrm{~d})$ & 1.54 & 0.023 & $\uparrow$ & 1.87 & 0.046 & $\uparrow$ \\
\hline Acetoacetate & $2.29(\mathrm{~s})$ & 2.33 & 0.021 & $\uparrow$ & 3.58 & 0.003 & $\uparrow$ \\
\hline Citrate & $2.54(\mathrm{~d})$ & 1.99 & 0.023 & $\uparrow$ & 1.84 & 0.033 & $\uparrow$ \\
\hline Methylamine & $2.63(\mathrm{~s})$ & 1.30 & 0.011 & $\uparrow$ & - & - & - \\
\hline Trimethylamine & $2.92(\mathrm{~s})$ & - & - & - & 1.62 & 0.027 & $\uparrow$ \\
\hline Choline & $3.20(\mathrm{~s})$ & 1.66 & 0.035 & $\uparrow$ & 1.70 & 0.044 & $\uparrow$ \\
\hline GPC & $3.22(\mathrm{~s})$ & - & - & - & 1.84 & 0.031 & $\uparrow$ \\
\hline
\end{tabular}

${ }^{a}$ O-Tyr $v s$. control, O-Tyr group compared with the control group; Dityr vs. control, Dityr group compared with the control group; VIP was obtained from OPLS-DA model. Compared with the control group, $\uparrow$ indicates a relative increase, and $\downarrow$ indicates a relative decrease in the integral value for the region containing the identified metabolite. Significant differences are set at $P<0.05$.

Table 6 List of differential urine metabolites among different groups ${ }^{a}$

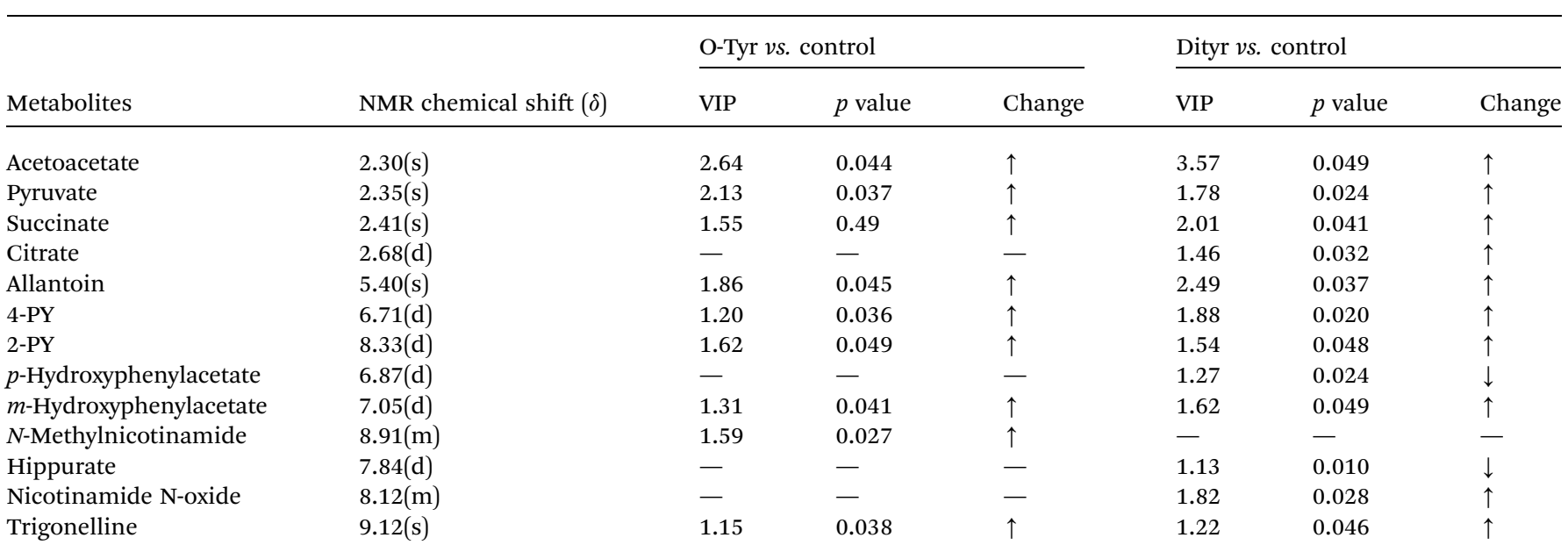

${ }^{a}$ O-Tyr $v s$. control, O-Tyr group compared with the control group; Dityr vs. control, Dityr group compared with the control group; VIP was obtained from OPLS-DA model. Compared with the control group, $\uparrow$ indicates a relative increase, and $\downarrow$ indicates a relative decrease in the integral value for the region containing the identified metabolite. Significant differences are set at $P<0.05$.

methyl-2-pyridone-5-carboxamide yphenylacetate, $N$-methylnicotinamide and trigonelline compared with the control group $(P<0.05$, Table 6). Dityr administration significantly increased the serum levels of propionate, isobutyrate, 3-hydroxybutyrate, acetoacetate, citrate, trimethylamine, choline and GPC, and decreased the serum levels of isoleucine, valine, alanine, betaine and $\alpha$ glucose compared with the control group $(P<0.05$, Table 5$)$. Also, DT administration significantly increased the urine levels of acetoacetate, pyruvate, succinate, citrate, allantoin, 4-PY, 2PY, $m$-hydroxyphenylacetate, nicotinamide N-oxide and trigonelline, and decreased the urine levels of $p$-hydroxyphenylacetate and hippurate compared with the control group $(P<0.05$, Table 6).

\section{Discussion}

Tyrosine (Tyr) is one of the major targets of protein oxidation; oxidation products of Tyr (such as Dityr and 3-NT) are universal biomarkers of protein oxidation and have been demonstrated to be associated with metabolic disorders in biological systems. ${ }^{\mathbf{1 8}}$ In this study, ${ }^{1} \mathrm{H}$ nuclear magnetic resonance spectroscopy was used to demonstrate the effects of O-Tyr and Dityr administration on metabolomes in the serum and urine of mice. Our results support the hypothesis that O-Tyr and Dityr administration can cause systemic metabolic alterations in serum and urine (Tables 5 and 6, respectively).

O-Tyr and Dityr administration induced oxidative stress responses in mice. Ketone bodies, such as acetoacetate and 3- 
hydroxybutyrate, are the products of $\beta$-oxidation of fatty acids in mitochondria. ${ }^{53,54}$ Increased serum acetoacetate and 3-hydroxybutyrate levels suggested that O-Tyr and Dityr administration promoted $\beta$-oxidation of fatty acids. The ratio of acetoacetate to 3-hydroxybutyrate is a useful indicator of the mitochondrial redox state. ${ }^{55}$ O-Tyr and Dityr administration were found to increase the urinary level of acetoacetate, but the concentration of 3-hydroxybutyrate in urine remained unchanged. As a result, acetoacetate/3-hydroxybutyrate ratios were increased, respectively. These results further suggest a highly oxidized cell state, which can be brought about by increased oxidation of fatty acids. Lipid oxidation can generate large amounts of electrons entering a mitochondrial respiratory chain to produce excess reactive oxygen species (ROS), ${ }^{56}$ thereby causing free radical oxidative damage. ${ }^{57,58}$ Oxidative stress followed by lipid oxidation is believed to be an important cause of destruction and damage to cell membranes. ${ }^{59}$ In support of this theory, O-Tyr administration increased the serum level of choline while DT administration increased the serum levels of choline and GPC, and decreased the level of betaine compared with the control group. Choline and GPC are essential for structural integrity of the cell membrane. ${ }^{\mathbf{6 0 , 6 1}}$ These compounds also have important functions in cell metabolism and signaling processes. ${ }^{\mathbf{6 2 , 6 3}}$ Oxidation of choline in liver mitochondria results in the formation of betaine. ${ }^{64,65}$ Some studies have shown that betaine functions to spare choline for the formation of phospholipids. ${ }^{6,67}$ In the present study, serum levels of choline and GPC were increased and betaine was decreased. A possible explanation is that structural integrity of the cell membrane was decreased.

Moreover, O-Tyr and Dityr administration induced elevation of urinary allantoin, which is an end product of the oxidation of uric acid by purine catabolism; this result also supports enhanced oxidative stress in agreement with previous studies that considered the elevation of urinary allantoin as an indicator for oxidative stress. ${ }^{68,69}$ Furthermore, elevation of urinary 4-PY, and 2-PY in mice administration with O-Tyr, and the elevation of urinary nicotinamide $\mathrm{N}$-oxide, 4-PY, and 2-PY in mice administration with Dityr suggested that metabolisms of nicotinate and nicotinamide (vitamin $\mathrm{B}_{3}$ ) were probably associated with progression of oxidative stress. Nicotinamide is a component of nicotinamide adenine dinucleotide (NAD) involved in intracellular respiration to oxidize fuel substrates, ${ }^{70}$ while nicotinamide N-oxide, 4-PY, and 2-PY are oxidation metabolites of nicotinamide in liver. ${ }^{44}$ Past research found that increased levels of nicotinamide N-oxide, 4-PY, and 2-PY imply elevated oxidative stress response in vivo. ${ }^{71}$ Therefore, the changes of these nicotinamide metabolites are probably also indications that O-Tyr and Dityr administration can induce oxidative stress responses in mice.

What's more, oxidative stress ultimately triggers an antioxidative response in an organism. Trigonelline and $\mathrm{N}$-methylnicotinamide are the respective methylated metabolites of nicotinate and nicotinamide, which can be generated during the conversion of S-adenosylmethionine to $\mathrm{S}$ adenosylhomocysteine during biosynthesis of cysteine, an essential amino acid of glutathione synthesis. ${ }^{51,72}$ A previous report suggests that elevated levels of $\mathrm{N}$-methylnicotinamide and decreased levels of nicotinate indicate increased oxidative stress response in vivo. ${ }^{73}$ In our study, the elevation of urinary trigonelline and $\mathrm{N}$-methylnicotinamide in mice administration with O-Tyr, and the elevation of urinary trigonelline in mice administration with Dityr, implied that mice can utilize an antioxidative vitamin $B_{3}$ cycle to decrease oxidative stress induced by O-Tyr and Dityr administration. The observation of an increased level of $m$-hydroxyphenylacetate, also implies antioxidative responses activated by O-Tyr and Dityr administration. This is because $m$-hydroxyphenylacetate is a rutin metabolite and an antioxidant. ${ }^{74}$

Taken together, O-Tyr and Dityr administration induced oxidative stress responses in mice. The increased levels of AOPPs, Dityr, 3-NT, and MDA (as markers of protein and lipid oxidative injury), decreased activities of T-AOC, SOD, and GSH$\mathrm{PX}$, and declined antioxidant enzymes mRNA expression of SOD1, SOD2, and GSH-PX, also supports such a theory (Fig. 2 and 3). Moreover, this is in agreement with results from our previous study that 24 week exposure to O-Tyr induces oxidative damage in rats. ${ }^{\mathbf{1 8 , 1 9}}$

A novel and unexpected finding from this study was that $\mathrm{O}-$ Tyr and Dityr administration promoted energy metabolism. OTyr and Dityr administration significantly decreased serum $\alpha$ glucose levels compared with the control group. Glucose is a major substrate for energy metabolism. The decreased levels of $\alpha$-glucose in serum suggested that O-Tyr and Dityr administration promoted glycolysis. Moreover, Dityr administration decreased serum alanine levels. Alanine is an important participant and regulator in glucose metabolism. ${ }^{75}$ Taken together, Dityr administration enhanced the glucose-alanine cycle metabolism. What's more, the observation of increased levels of pyruvate in urine suggested that O-Tyr and Dityr administration led to a promotion of the TCA cycle. This is because pyruvate is a key metabolite that is important in both glycolysis and the TCA cycle, and can be converted into acetylCoA by decarboxylation and transported into the TCA cycle under aerobic conditions. ${ }^{76}$ Increased pyruvate levels revealed that generation of acetyl-coenzymeA (acetyl-CoA) was upregulated, resulting in promotion of the TCA cycle. In support of this view, O-Tyr significantly increased serum citrate levels, and urine succinate levels, and Dityr administration significantly increased serum citrate levels, and urine citrate and succinate levels. Citrate and succinate are important intermediates of the TCA cycle. A change in the contents of citrate and succinate would reflect a change in the metabolic rate of the TCA cycle. ${ }^{77,78}$ Increased levels of citrate and succinate in serum and urine suggests that the TCA cycle is promoted by administration with O-Tyr and Dityr. Our results also showed that levels of branched-chain amino acids were decreased by O-Tyr and Dityr administration. A possible reason is that oxidative stress-induction increased energy expenditure and also caused elevated consumption of amino acids, such as isoleucine, alanine, and valine, to provide energy.

Another novel and unexpected finding from this study was that O-Tyr and Dityr administration caused changes in gut microbiota functions. Previous research from our group has 
shown that oxidized casein administration induced a decrease of intestinal Lactobacillus and increased intestinal Escherichia coli and Enterococcus in mice. ${ }^{79}$ Intestinal microbes convert dietary non-digestible fibers into short-chain fatty acids (acetate, propionate, butyrate, and isobutyrate) and other nutrients that can be used by the mammalian host as energy sources or as precursors for fatty acid synthesis. ${ }^{80}$ In this study, we found that O-Tyr and Dityr administration significantly increased serum propionate and isobutyrate levels, implying that O-Tyr and Dityr administration caused changes in gut microbiota functions. In support of this theory, serum levels of methylamine in the O-Tyr group and trimethylamine in the Dityr group were increased compared with the control group. Serum nitrogenous compounds (methylamine, dimethylamine, trimethylamine, and TMAO) are microbial metabolites of carbohydrates and amino acids, which are probably produced in the lumen of the small and large intestines. ${ }^{23,81}$ Hippurate is one of the co-metabolites between gut microbiota and a host, and is a product of the conjugation of glycine and benzoic acid, ${ }^{82}$ which takes place in mitochondria of the liver and kidney. ${ }^{83,84}$ Benzoic acid is a product of the intestinal microbial degradation of aromatic compounds in food..$^{85-87}$ Therefore, a change in the excretion of hippurate suggests an alteration in the functional metabolism of microbiota.$^{88}$ In this study, we found a marked elevation in the levels of hippurate in the urine of mice administration with Dityr; this result also supports the view that Dityr administration changes intestinal microbial metabolism. Moreover, $p$-hydroxyphenylacetate is a metabolite of tyrosine processed by enteric bacteria. Decreased levels of $p$ hydroxyphenylacetate in urine also confirmed the association of Dityr administration with a gut microbiota disturbance.

In this work, changes in these metabolites of intestinal microflora may be explained by an increased number and/or altered activity of intestinal microflora. Mammalian metabolism is significantly influenced by interactions with the complex gut microbiota. An introduction of O-Tyr and Dityr ingestion into the mammalian system may displace baseline mammalianto-microbial behavior, thereby disrupting microbial populations and eventually affecting metabolism. Gut microbiota significantly affect development and structure of the intestinal epithelium, digestive and absorptive properties of the intestine, and the host immune system. ${ }^{89}$ Possible disturbances of gut microbiota by O-Tyr and Dityr administration can affect health; thus, microbiological identification of specific changes in the microbiota community can help address metabolic implications of O-Tyr and Dityr administration.

\section{Conclusions}

This study has shown that O-Tyr and Dityr administration affects the urine and serum metabolome of mice. O-Tyr and Dityr administration can cause oxidative stress and some common systemic metabolic changes, including energy metabolism, glucose-alanine cycle metabolism, glycolysis, cell membrane metabolism, vitamin- $\mathrm{B}_{3}$ metabolism, and gut microbiota metabolism. Therefore, we need additional intake of antioxidant and vitamin- $\mathrm{B}_{3}$ when much more oxidative proteins are ingested. These results are very important for animal and human food safety and disease prevention. To the best of our knowledge, this study is the first in vivo report on the response of animal biological systems to O-Tyr and Dityr administration. Future studies may be directed toward a mechanistic understanding of the effects of O-Tyr and Dityr on animal tissue intermediary metabolism, especially in terms of the associations between deficiency of B vitamins and O-Tyr and Dityr administration.

\section{Conflict of interest}

The authors declare that they have no conflict of interest. All authors listed have contributed to the work, and agreed to submit the manuscript. No part of the work has been published before.

\section{Ethical approval}

All procedures performed in studies involving animals were in accordance with the ethical standards laid down in the guidelines of Laboratory Animals Care of Jiangsu Province (China) and in the 1964 Declaration of Helsinki and its later amendments.

\section{Acknowledgements}

This research was supported by program of "Collaborative innovation center of food safety and quality control in Jiangsu Province", the National Natural Science Foundation of China (No. 31571841), State Key Laboratory of Food Science and Technology of Jiangnan University in China (SKLF-ZZB-201609), and China Postdoctoral Science Foundation (2015M571669).

\section{References}

1 B. Halliwell, M. A. Murcia, S. Chirico and O. I. Aruoma, Crit. Rev. Food Sci. Nutr., 1995, 35, 7-20.

2 M. N. Lund, M. Heinonen, C. P. Baron and M. Estevez, Mol. Nutr. Food Res., 2011, 55, 83-95.

3 W. Zhang, S. Xiao and D. U. Ahn, Crit. Rev. Food Sci. Nutr., 2013, 53, 1191-1201.

4 E. R. Stadtman and R. L. Levine, Ann. N. Y. Acad. Sci., 2000, 899, 191-208.

5 M. Utrera and M. Estevez, J. Agric. Food Chem., 2012, 60, 8002-8011.

6 E. R. Stadtman, Annu. Rev. Biochem., 1993, 62, 797-821.

7 T. Henle, Mol. Nutr. Food Res., 2007, 51, 1075-1078.

8 Z. L. Li, L. Mo, G. Le and Y. Shi, Food Chem. Toxicol., 2014, 64, 86-93.

9 F. Xie, S. Sun, A. Xu, S. Zheng, M. Xue, P. Wu, J. H. Zeng and L. Bai, Cell Death Dis., 2014, 5, e1006.

10 Z. M. Zhong, L. Bai and J. T. Chen, Cell. Physiol. Biochem., 2009, 24, 105-114.

11 M. J. Davies, Biochim. Biophys. Acta, 2005, 1703, 93-109.

12 A. Hohn, J. Konig and T. Grune, J. Proteomics, 2013, 92, 132159. 
13 G. Cohen, S. Yakushin and D. Dembiec-Cohen, Anal. Biochem., 1998, 263, 232-239.

14 J. R. Crowley, K. Yarasheski, C. Leeuwenburgh, J. Turk and J. W. Heinecke, Anal. Biochem., 1998, 259, 127-135.

15 J. W. Heinecke, F. F. Hsu, J. R. Crowley, S. L. Hazen, C. Leeuwenburgh, D. M. Mueller, J. E. Rasmussen and J. Turk, Methods Enzymol., 1999, 300, 124-144.

16 K. Hensley, K. S. Williamson and R. A. Floyd, Free Radical Biol. Med., 2000, 28, 520-528.

17 C. Leeuwenburgh, P. A. Hansen, J. O. Holloszy and J. W. Heinecke, Am. J. Physiol., 1999, 276, R128-R135.

18 Z. L. Li, Y. Shi, G. Le, Y. Ding and Q. Zhao, Oxid. Med. Cell. Longevity, 2016, 2016, 3123294.

19 Z. L. Li, Y. Shi, Y. Ding, Y. Ran and G. Le, Amino Acids, 2017, 49, 241-261.

20 Y. Ran, B. Yan, Z. Li, Y. Ding, Y. Shi and G. Le, Physiol. Behav., 2016, 164, 292-299.

21 D. P. Jones, Y. Park and T. R. Ziegler, Annu. Rev. Nutr., 2012, 32, 183-202.

22 J. K. Nicholson, J. C. Lindon and E. Holmes, Xenobiotica, 1999, 29, 1181-1189.

23 S. Rezzi, Z. Ramadan, L. B. Fay and S. Kochhar, J. Proteome Res., 2007, 6, 513-525.

24 C. Stella, B. Beckwith-Hall, O. Cloarec, E. Holmes, J. C. Lindon, J. Powell, F. van der Ouderaa, S. Bingham, A. J. Cross and J. K. Nicholson, J. Proteome Res., 2006, 5, 2780-2788.

25 Q. He, X. Kong, G. Wu, P. Ren, H. Tang, F. Hao, R. Huang, T. Li, B. Tan, P. Li, Z. Tang, Y. Yin and Y. Wu, Amino Acids, 2009, 37, 199-208.

26 Z. Ruan, Y. Yang, Y. Wen, Y. Zhou, X. Fu, S. Ding, G. Liu, K. Yao, X. Wu, Z. Deng, G. Wu and Y. Yin, Amino Acids, 2014, 46, 2681-2691.

27 G. Liu, Y. Wang, Z. Wang, J. Cai, X. Lv and A. Zhou, J. Agric. Food Chem., 2011, 59, 5572-5578.

28 G. Liu, T. Fang, T. Yan, G. Jia, H. Zhao, Z. Huang, X. Chen, J. Wang and B. Xue, J. Agric. Food Chem., 2014, 62, 90359042.

29 G. Liu, L. Xiao, T. Fang, Y. Cai, G. Jia, H. Zhao, J. Wang, X. Chen and C. Wu, PLoS One, 2014, 9, e115561.

30 F. A. Van Dorsten, C. A. Daykin, T. P. Mulder and J. P. Van Duynhoven, J. Agric. Food Chem., 2006, 54, 6929-6938.

31 Z. Ruan, Y. Yang, Y. Zhou, Y. Wen, S. Ding, G. Liu, X. Wu, P. Liao, Z. Deng, H. Assaad, G. Wu and Y. Yin, Amino Acids, 2014, 46, 2219-2229.

32 Y. Zhang, B. Wu, Z. Y. Zhang and S. P. Cheng, J. Hazard. Mater., 2011, 190, 515-519.

33 Q. He, H. Tang, P. Ren, X. Kong, G. Wu, Y. Yin and Y. Wang, J. Proteome Res., 2011, 10, 5214-5221.

34 C. Xiao, F. Hao, X. Qin, Y. Wang and H. Tang, Analyst, 2009, 134, 916-925.

35 T. Kurahashi, A. Miyazaki, S. Suwan and M. Isobe, J. Am. Chem. Soc., 2001, 123, 9268-9278.

36 X. Zhu, H. Lei, J. Wu, J. V. Li, H. Tang and Y. Wang, J. Proteome Res., 2014, 13, 4436-4445.

37 T. W. Fan, R. M. Higashi, A. N. Lane and O. Jardetzky, Biochim. Biophys. Acta, 1986, 882, 154-167.
38 M. Kriat, S. Confort-Gouny, J. Vion-Dury, M. Sciaky, P. Viout and P. J. Cozzone, NMR Biomed., 1992, 5, 179-184.

39 G. M. Liu, G. J. Yang, T. T. Fang, Y. M. Cai, C. M. Wu, J. Wang, Z. Q. Huang and X. L. Chen, RSC Adv., 2014, 4, 23749-23758.

40 J. Trygg and S. Wold, J. Chemom., 2002, 16, 119-128.

41 J. Jansson, B. Willing, M. Lucio, A. Fekete, J. Dicksved, J. Halfvarson, C. Tysk and P. Schmitt-Kopplin, PLoS One, 2009, 4, e6386.

42 Z. J. Zou, Z. H. Liu, M. J. Gong, B. Han, S. M. Wang and S. W. Liang, Phytomedicine, 2015, 22, 333-343.

43 D. Granato, V. M. D. Calado and B. Jarvis, Food Res. Int., 2014, 55, 137-149.

44 D. Li, L. L. Zhang, F. C. Dong, Y. Liu, N. Li, H. H. Li, H. H. Lei, F. H. Hao, Y. L. Wang, Y. Zhu and H. R. Tang, J. Proteome Res., 2015, 14, 2237-2254.

45 G. M. Liu, T. Yan, J. Wang, Z. Q. Huang, X. L. Chen, G. Jia, C. M. Wu, H. Zhao, B. Xue, L. Xiao and J. Y. Tang, J. Agric. Food Chem., 2013, 61, 11212-11221.

46 T. Suna, A. Salminen, P. Soininen, R. Laatikainen, P. Ingman, S. Makela, M. J. Savolainen, M. L. Hannuksela, M. Jauhiainen, M. R. Taskinen, K. Kaski and M. AlaKorpela, NMR Biomed., 2007, 20, 658-672.

47 A. Vehtari, V. P. Makinen, P. Soininen, P. Ingman, S. M. Makela, M. J. Savolainen, M. L. Hannuksela, K. Kaski and M. Ala-Korpela, BMC Bioinf., 2007, 8, S8.

48 D. S. Wishart, D. Tzur, C. Knox, R. Eisner, A. C. Guo, N. Young, D. Cheng, K. Jewell, D. Arndt, S. Sawhney, C. Fung, L. Nikolai, M. Lewis, M. A. Coutouly, I. Forsythe, P. Tang, S. Shrivastava, K. Jeroncic, P. Stothard, G. Amegbey, D. Block, D. D. Hau, J. Wagner, J. Miniaci, M. Clements, M. Gebremedhin, N. Guo, Y. Zhang, G. E. Duggan, G. D. MacInnis, A. M. Weljie, R. Dowlatabadi, F. Bamforth, D. Clive, R. Greiner, L. Li, T. Marrie, B. D. Sykes, H. J. Vogel and L. Querengesser, Nucleic Acids Res., 2007, 35, D521-D526.

49 Y. Cai, F.-h. Hao and Y.-l. Wang, Chin. J. Magn. Reson., 2013, 1, 007.

50 X. J. Zhao, C. Huang, H. Lei, X. Nie, H. Tang and Y. Wang, J. Proteome Res., 2011, 10, 5183-5190.

51 C. Y. Huang, H. H. Lei, X. J. Zhao, H. R. Tang and Y. L. Wang, J. Proteome Res., 2013, 12, 537-545.

52 W. K. Ren, J. Yin, W. Gao, S. Chen, J. L. Duan, G. Liu, T. J. Li, N. Z. Li, Y. Y. Peng and Y. L. Yin, $R S C A d v .$, 2015, 5, 5955059555.

53 M. Lopes-Cardozo and S. G. van den Bergh, Biochim. Biophys. Acta, 1974, 357, 53-62.

54 A. B. Wojtczak, Biochem. Biophys. Res. Commun., 1968, 31, 634-640.

55 P. Schonfeld, R. Bohnensack, G. Bohme and W. Kunz, Biochim. Biophys. Acta, 1983, 42, 3-13.

56 Y. An, W. Xu, H. Li, H. Lei, L. Zhang, F. Hao, Y. Duan, X. Yan, Y. Zhao, J. Wu, Y. Wang and H. Tang, J. Proteome Res., 2013, 12, 3755-3768.

57 B. Halliwell and S. Chirico, Am. J. Clin. Nutr., 1993, 57, 715S724S; discussion 724S-725S.

58 D. Wu and A. I. Cederbaum, Alcohol Res. Health, 2003, 27, 277-284. 
59 R. Mittler, Trends Plant Sci., 2002, 7, 405-410.

60 N. F. Sheard and S. H. Zeisel, Nutrition, 1989, 5, 1-5.

61 S. H. Zeisel, Nutrition, 2000, 16, 669-671.

62 J. Klein, J. Neural Transm., 2000, 107, 1027-1063.

63 S. H. Zeisel and J. K. Blusztajn, Annu. Rev. Nutr., 1994, 14, 269-296.

64 P. I. Holm, P. M. Ueland, G. Kvalheim and E. A. Lien, Clin. Chem., 2003, 49, 286-294.

65 J. J. De Ridder and K. van Dam, Biochim. Biophys. Acta, 1973, 291, 557-563.

66 M. T. Kidd, P. R. Ferket and J. D. Garlich, World's Poult. Sci. J., 1997, 53, 125-139.

67 Z. M. Yao and D. E. Vance, J. Biol. Chem., 1989, 264, 1137311380.

68 M. Grootveld and B. Halliwell, Biochem. J., 1987, 243, 803808.

69 T. Mikami, K. Kita, S. Tomita, G. J. Qu, Y. Tasaki and A. Ito, Free Radical Res., 2000, 32, 235-244.

70 H. H. Li, Y. P. An, L. L. Zhang, H. H. Lei, L. M. Zhang, Y. L. Wang and H. R. Tang, J. Proteome Res., 2013, 12, 5520-5534.

71 D. Li, L. Zhang, F. Dong, Y. Liu, N. Li, H. Li, H. Lei, F. Hao, Y. Wang, Y. Zhu and H. Tang, J. Proteome Res., 2015, 14, 2237-2254.

72 X. J. Zhao, F. H. Hao, C. Y. Huang, M. Rantalainen, H. H. Lei, H. R. Tang and Y. L. Wang, J. Proteome Res., 2012, 11, 47124721.

73 G. Liu, T. Yan, J. Wang, Z. Huang, X. Chen, G. Jia, C. Wu, H. Zhao, B. Xue, L. Xiao and J. Tang, J. Agric. Food Chem., 2013, 61, 11212-11221.
74 S. Baba, T. Furuta, M. Horie and H. Nakagawa, J. Pharm. Sci., 1981, 70, 780-782.

75 P. Felig, Metab., Clin. Exp., 1973, 22, 179-207.

76 P. Liao, L. Wei, X. Zhang, X. Li, H. Wu, Y. Wu, J. Ni and F. Pei, Anal. Biochem., 2007, 364, 112-121.

77 S. A. Barinova, Mikrobiologiia, 1960, 29, 21-27.

78 H. A. Krebs, Adv. Enzyme Regul., 1970, 8, 335-353.

79 W. Fang, J. Sun, Z. L. Li, G. Le and Y. Shi, Chin. J. Microecol., 2012, 4, 193-196.

80 R. E. Ley, P. J. Turnbaugh, S. Klein and J. I. Gordon, Nature, 2006, 444, 1022-1023.

81 G. W. Tannock, Appl. Environ. Microbiol., 2004, 70, 31893194.

82 H. B. Lewis, J. Biol. Chem., 1914, 18, 225-231.

83 J. Caldwell, J. R. Moffatt and R. L. Smith, Xenobiotica, 1976, 6, 275-280.

84 S. J. Gatley and H. S. Sherratt, Biochem. J., 1977, 166, 39-47. 85 D. T. Gilbson, Science, 1968, 161, 1093-1097.

86 J. K. Nicholson and I. D. Wilson, Nat. Rev. Drug Discovery, 2003, 2, 668-676.

87 A. R. Rechner, G. Kuhnle, P. Bremner, G. P. Hubbard, K. P. Moore and C. A. Rice-Evans, Free Radical Biol. Med., 2002, 33, 220-235.

88 E. Holmes, J. V. Li, T. Athanasiou, H. Ashrafian and J. K. Nicholson, Trends Microbiol., 2011, 19, 349-359.

89 J. Xu and J. I. Gordon, Proc. Natl. Acad. Sci. U. S. A., 2003, 100, 10452-10459. 